\title{
Research on the Influence of the Trust of the Government in Different Order on the Environmental Performance Evaluation of the People s Government and the Intermediary Mechanism
}

\author{
${ }^{I}$ School of Marxism, Wuhan University of Technology, Wuhan, P.R. China \\ ${ }^{2}$ School of Marxism, Wuhan University of Technology, Wuhan, P.R. China \\ ${ }^{3}$ School of Marxism, Wuhan University of Technology, Wuhan, P.R. China \\ a2839312992@qq.com \\ b153781650@qq.com \\ c1348388177@qq.com
}

Li Xia ${ }^{1, a}$, Zhou Wenqian" ${ }^{2,}$, Chang $\mathrm{Yi}^{3, \mathrm{c}}$

\section{ABSTRACT}

There is a big difference in the environmental performance evaluation of the Central and local governments. One of the important psychological factors that lead to the difference in the evaluation is the People's trust in the government. On the basis of fully considering the public trust psychology, this paper reviews the theory of the relationship between the trust of the government and the public's environmental performance evaluation, and from the subjective and objective aspects of the intermediary factors between them are sorted out, and then put forward relevant measures to improve the public on the government's environmental performance evaluation.

Keywords: Government Trust, government environmental performance, influence, intermediary mechanism

\section{差序政府信任对民众政府环境绩效评价的影响及 中介机制探究}

\author{
1 武汉理工大学马克思主义学院, 湖北, 武汉, 中国 \\ 2 武汉理工大学马克思主义学院, 湖北, 武汉, 中国 \\ 3 武汉理工大学马克思主义学院, 湖北, 武汉, 中国 \\ a2839312992@qq.com \\ b153781650@qq.com \\ c1348388177@qq.com
}

李霞 $1, \mathrm{a}$, 周雯倩 $2, \mathrm{~b}$, 昌意 ${ }^{3, \mathrm{c}}$,

摘要: 环境污染愈发严峻, 央地政府为改善环境都采取了相应措施。但民众对央地政府环境绩效评价却差异 较大，导致评价不同的重要心理因素之一是民众的政府信任程度。本文在充分考虑公众的差序政府信任心理的 基础上，对差序政府信任和民众的环境绩效评价关系的理论进行回顾，并且从主客观两方面就它们二者之间的 中介因素的相关理论进行了梳理，进而提出相关措施以改善民众对政府环保绩效评价。

关键字：差序政府信任；政府环境绩效；影响；中间作用机制 


\section{1.导论}

改革开放后，经济迅速发展，但环境污染愈发严 峻，近年来不断出现抗议、示威等环境群体性事件, 而突破该困境的关键就是提高公众对政府环境绩效 评价。公众对央地政府环境绩效评价差异较大，其重 要心理因素之一是公众对政府的信任程度。许多学者 就政府信任对公众评价政府环境绩效的影响进行探 讨, 卢春天等通过 CGSS 数据分析发现在影响公众评 价政府环保工作的因素中, 政府信任水平这一变量的 解释力最强。但政府信任对公众政府环境绩效评价的 影响及其中介机制是什么？相关研究还未涉及。

而差序政府信任，作为处于转型期的中国特有的 政治现象, 指公民对中央政府的高信任度、对地方政 府的低信任度。这与我们研究的公众对央地政府环保 绩效评价具有差异性可能存在联系, 在公众本身固有 或是后天产生的差序政府信任心理影响下, 通过一定 的中介因素, 使得他们对央地政府环保绩效的评价不 一致。在公众进行评价时, 差序政府信任对于央地政 府环境绩效评价差异的产生发挥了什么作用? 影响 公众评价政府环境绩效的重要影响因素是公众对政 府的信任, 但是否会受到绩效标准、目标、指标设置 等客观因素和公众个人的情绪状态、政治参与状况等 主观因素影响?

基于以上讨论, 本文的理论突破口是充分考虑 公众的差序政府信任心理，探讨差序政府信任这种 中国独特的心理学现象对于央地政府环境绩效评 价差产生的影响, 进而对其中介因素的相关理论进 行梳理并提出相关建议。

\section{2.差序政府信任对于民众评价政府环境绩效 的影响}

提高目前, 公众评价政府环保工作的研究主要从 以下方面进行研究, 即公众评价政府环保工作的理论 基础，公众参与政府环境绩效评价的现状、特点、问 题, 如何构建新的绩效评价体系和影响公众评价政府 环境绩效的因素研究等。

公众评价政府环境绩效的文献多从公众满意度 角度进行研究, 偏向定性研究, 实证研究较少。从政 府层级的角度, 政府环境绩效区分为中央政府环境绩 效和地方政府环境绩效, 不少学者基于中国综合社会 调查数据的研究证明公众对于中央政府的环保绩效 评价是高于地方环保绩效评价(周全, 2016; 王胜利, 2019)。

公众对公共服务绩效评价包括客观绩效评价和 主观绩效评价, 从客观绩效评价层面来说, 地区宏观 的经济发展状况（张成、朱乾龙,2012）、城乡差距和 地区差距（周全，2016; 王胜利,2019）、环境污染状 况（英格尔哈特，1995; 卢春天，2015）等都对公众 评价政府环境绩效具有显著影响。
在个人层面上，教育背景、职业、收入、环境知 识水平、个人社会的经济特征、对环境政策的态度等 影响政府的环境绩效评价。现有学者从个人心理学的 观点进一步研究了政府信任心理的影响。政府信任是 指公众对政府的信赖程度，其评价标准是政府的行为 是否满足公众的期待。目前的研究表明, 现代中国各 级政府之间的政治信任分布具有非同一性特征。公众 对中央政府的信赖度很高, 地方政府（特别是基层政 府）的不满很多。到 2012 年, 李连江正式提出了“差 序政府信任”这一概念：差序政府信任是中央政府、 省、市、县、乡对政府的信任度逐渐下降。同时，根 据现有国内外的研究表明, 公众信任度越高, 对政府 环境绩效评价就越高。

因此, 基于现有研究中国广泛存在的这种差序政 府信任心理和基于 CGSS 数据证明的央地政府环境绩 效评价存在的差异, 我们可以发现差序政府信任心理 很有可能就是公众对于中央政府环境绩效评价差异 产生的一个重要原因。

\section{3. 差序政府信任影响民众评价政府环境绩效 评价的可能中介机制探究}

本文所论述的差序政府信任影响公众评价政府 环境的中介机制是从主客观角度进行探讨, 即个体的 差序政府信任心理经个体其他主观心理因素以及客 观的环境状况、评价体系要素等中介因素对公众评价 政府环境绩效的影响，并就主观作用机制和客观作用 机制所包含的各个可能的中介因素发生作用过程中 的主体及行为动机、作用过程和作用路径与效果进行 分析和探讨。

\section{1. 差序政府信任影响民众评价政府环境绩效 评价的主观作用机制}

\subsection{1. 环境污染感知与政府环境绩效评价}

公众通过对自己的环境污染情况的感知来评价 政府的环境性能，而个体信任感往往会使得个体在评 价政府环境绩效的过程中有意识的忽略或夸大政府 环境保护过程中的缺点和不足, 影响个人的环境污染 感知, 从而影响公众对于环境绩效评价的影响。相关 研究表明, 公众对地方政府信任水平越高, 其环境风 险感知越低, 那么公众的环境污染认知在政府信任和 政府环境绩效评价中间就有可能起遮掩效应，公众在 高政府信任的影响下，产生对于环境污染的不客观认 识使得公众对于政府环境绩效的评价更高。

\subsection{2. 公众自感健康与政府环境绩效评价}

有研究发现信任度会对公众自感健康会产生影 响, 而王胜利等研究发现自感健康负向影响个体对中 央政府环保工作的评价。这说明自感健康可能也是政 府信任对公众评价政府环境绩效作用过程中的一个 
中介因素。公众对于政府越信任，进而对于自身健康 的认识和评价也会变高, 从而弱化环境污染对于自身 健康的影响，对于政府的环境绩效作出更高的评价。

\subsection{3. 政治参与与政府环境绩效评价}

公众参与政治程度的积极性在一定程度上受到 公众对政府信任程度的影响。公众信任度高, 他们会 积极参加当地政府发动的活动, 影响政府的环境性能 评价。一位学者分析，通过对我国基层村民委员会选 举影响因素的调查, 是否参加村民委员会选举的重要 决定因素是对乡镇政府的信任度。公众对基层政府的 信赖度越高, 就越有可能参加村民委员会选举。随着 参加度的提高, 政府工作的难易理解, 政府的环境性 能评价也有可能提高。因此, 政府的信任可能会通过 参与政治影响公众对政府表现的评价。

\subsection{4.环境关心与政府环境绩效评价}

当公众的环境关心水平不断提升的时候, 他们渴 望优良的环境, 因此他们对政府的环境行为有着更为 严格的评判标准。因此, 有学者认为公众对于环境问 题有较高的关心度和感知度时会消极影响他们对政 府环保工作的评价。所以公众对政府的信任就有可能 通过对环境关心的影响, 从而影响公众对于政府绩效 的评价更高。

\section{2. 差序政府信任影响民众评价政府环境绩效 评价的客观作用机制}

\subsection{1. 环境政策支持与政府环境绩效评价}

信任合作是影响公众参与环境治理的重要内部 影响因素之一, 公众政治信任水平越高, 对公共政策 的支持度就越高。环境政策支持与否, 从某种程度上 来说, 代表了公众对于政府的一种态度, 因此, 政府 信任就有可能正向影响公众的对于相关环境政策的 支持度进而影响对于公众评价政府环境绩效。

\subsection{2. 政府环境治理绩效与政府环保绩效评价}

根据政府环境治理绩效和表现, 公众对政府环境 工作进行评价, 因此政府只有真正实现环境优化, 才 能获得公众更高评价。政府信任会影响政府的治理绩 效, 在中国存在差序政府信任现象，而中国治理体制 又是“上下分治的治理体制”的治理体制, 中央政府机 构主要负责制定环境治理政策, 地方政府的职责则是 相关政策的落地与执行。而且地方官员是制度实施过 程中具体和公众进行接触的群体, 可能会产生许多不 愉快的经历。在差序政府信任心理的影响下, 这种不 愉快的经历可能使得公众对于地方政府的环境治理 工作支持度下降，从而产生央地政府环境治理的差 异, 进而造成公众对中央政府的环境绩效评价高于地 方。

\subsection{3. 政府绩效评价体系与政府环境绩效评价}

政府绩效评价体系与公众合法权益与有着密切 联系, 因此, 公众会影响政府绩效评价中的主要内容、 标准、方式等。但政府环境绩效评价体系的构建, 各 个测量指标的确定, 政府扮演的都是主导者和操纵者 的角色。不管是公众还是专家可能最终都是在为政府 想要的绩效评价结果服务。公众的政府信任这一公众 心理很可能就是政府调整相关的绩效评价体系各部 分内容的一个影响因素, 进而影响最终的环境绩效评 价。

\subsection{4. 绩效评价内容与政府环境绩效评价}

ACSI 评价模型认为, 在建立评价指标体系时, 将公众的满意度纳入政府绩效评价体系, 公众满意度 将对政府绩效的评价产生重要影响。在现有的研究 中, 政府的信任度越高, 公众的满足度越高, 两者的 关系就越显著发展，但是中央政府的信赖与影响有差 异。因此, 公众政府的信任会影响公众的满意度, 影 响公众对政府性能的评价。

\subsection{5. 绩效评价主体与政府环境绩效评价}

中国政府绩效评价的主体从上级政府转变为政 府自我再到公众。最初的两种评价主体都是政府, 政 府自评或者政府上下级评价的弊端很明显, 比如外部 监督缺失、评估信息封闭等。而公众参与到政府绩效 评价, 有利于改善政府与公众之间的关系, 有利于提 高公众对政府信任程度，有利于政府更好的为公众服 务。

\subsection{6.绩效评价方式与政府环境绩效评价}

政府绩效评价方式主要有三种：指标考核、公众 评议和调查, 但现有研究发现, 公众评议政府行为的 权重较低, 而政府内部评价仍占较大权重。因此公众 的政府信任状况可能就会影响政府绩效评价方法的 选择和各部分方式采用的权重比例, 进而影响整体的 政府环境绩效的评价结果。公众的政府信任程度越 高, 政府越可能会加大相关公众评议等形式的政府环 境绩效评价方式, 以提高整体的政府环保绩效结果。

\section{4. 结论}

本文从主观和客观路径出发, 通过对差序政府信 任影响民众政府环境绩效评价的可能中介因素的文 献梳理发现: 从主观中介影响机制出发, 环境污染感 知、公众自感健康、政治参与和环境关心等因素都有 可能会在差序政府信任心理的影响下进而影响民众 对于政府环境绩效的评价。从客观中介影响机制出 发, 民众现实环境政策支持情况，政府客观环境治理 绩效状况，政府绩效评价体系、内容、主体、方式等 因素在受差序政府信任心理影响的同时也会对民众 
评价政府环境绩效有影响。这样就构建起了一个差序 政府信任影响民众评价政府环境绩效的框架体系，对 于进一步改善政府的信任水平和绩效评价水平提供 了可能的方向。

\section{5.启示与建议}

\section{1. 完善地方政府的环保机制}

地方政府的环境性能评价越来越低, 是因为地方 政府在环境治理和保护方面有缺陷和脆弱性, 因此要 求地方政府努力提高环境治理水平, 强化环境保护机 制。对高污染型企业进行强度监督和控制，全方位、 高效保障, 保证各地区不发生严重的环境污染事件, 保障各公众在健康环境中生活。

\section{2. 加强地方政府对环境问题的响应性}

为了提高公众对地方政府环境绩效的评价, 地方 政府有必要提高对环境问题的应对能力。首先, 地方 政府需要公众对高环境质量的需求。分析显示, 社会 经济地位影响公众对环境问题的感知, 中收入阶层渴 望更高质量环境。因此, 地方政府应该采取措施加强 环境保护和治理, 及时甚至提前响应这个公众的需 要。其次, 地方政府需要提高政府环境治理的客观成 果。因此, 地方政府不断提高环境保护和污染防治效 果, 让公众真正感受到环境的改善, 提高公众满意度, 从而提高公众对地方政府环境绩效的评价。

\section{3. 加强公众对环境保护的监督管理和分散参 加}

由于大部分公众没有参加环境保护, 地方政府对 环境保护效果的评价很低, 所以地方政府必须积极鼓 励参加环境保护, 加强监督管理和分散参加。参与监 督管理是公众的参与, 为了保证更明确更详细的系统 设计, 给公众实质的参与能力和力量, 需要提高科学 决策过程的民主化程度, 让公众参与“参与”本身。分 散参加是指在非制度化、非权威的情况下参加活动需 要适当的指导, 因此地方政府应该加强公众对环境保 护的监督管理和分散参加。

\section{4.实现地方政府和公众在环境保护方面的良 性对话}

邓正来和景跃进于 1992 年提出了“公民社会和国 家关系的良性对话说”, 该理论指出需要提供更加可 靠和有效的平台来让公众更好参与环境治理。研究表 明, 公众和政府如果一方关注环境问题, 就会促进生 态环境的改善。另调查结果显示, 如果公众对政府的 依赖性高, 参加环境对策的意愿就会下降。因此, 公 众对地方政府环境保护性能评价低的重要原因是公 众过度依赖地方政府, 而变得消极地接受地方政府对 环境的控制。为了提高地方政府对环境保护的公众性
能评价, 必须努力实现环境保护中的二者的良性互 动, 公众也要参加环境保护, 与地方政府形成合作关 系, 提高地方政府的信赖度。

\section{项目基金}

本文为武汉理工大学国家级大学生创新 创业训练计划项目 (项目编号为 S202010497139）“差序政府视角下公众对政府 环保绩效评价研究——武汉市公众调查为 例”资助

\section{REFERENCES}

[1] Wang Shengli, Zhang Yan. Study on the influencing factors of government environmental job satisfaction — based on CGSS 2015 data analysis [J]. Ecological economy, 2019,35(06): 182-187.

[2] Li Wen-bin, Li Shao-shu, Li Yu. Environmental Awareness, environmental participation and local government environmental satisfaction [J]. Leadership Science Forum, 2016(21): 59-72.

[3] Wang Yuming. Public Social Trust and government performance evaluation [J]. Journal of Yunnan University of Administration, 2019,21(06): 154-160.

[4] Deng Zhenglai, Jing Yuejin. Construction of Chinese civil society [J]. Chinese social sciences, 1992, (1) 